Utah State University

DigitalCommons@USU

Spring 2013

\title{
Who Uses this Stuff, Anyway? An Investigation of Who Uses the DigitalCommons@USU
}

Andrew Wesolek

Utah State University

Follow this and additional works at: https://digitalcommons.usu.edu/lib_pubs

Part of the Library and Information Science Commons

\section{Recommended Citation}

Please use publisher's recommended citation

This Conference Paper is brought to you for free and open access by the Libraries at DigitalCommons@USU. It has been accepted for inclusion in Library Faculty \& Staff

Publications by an authorized administrator of DigitalCommons@USU. For more information, please contact digitalcommons@usu.edu.

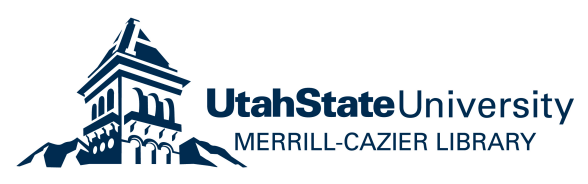




\begin{abstract}
:
Much professional literature is devoted to developing content and faculty buy-in for institutional repositories. However, little is known about the end users of these repositories. The Utah State University Institutional Repository (IR) has reached a stage of maturity in which it is necessary to begin shifting our efforts from encouraging faculty buy-in to understanding our end-users and their needs. This presentation focused on: 1 . how USU's IR reached its mature stage, 2 . the results of a brief survey of the end users of our repository, and 3. how these results have informed the further development of our IR.
\end{abstract}

\title{
Keywords:
}

Institutional Repositories, Repository End Users, Open Access, Digital Commons, 


\section{Background Information}

Utah State University has an enrollment of about 28,000 students. These students are located both on our main Logan Campus, situated in beautiful Cache Valley Utah, as well as a number of regional campuses and classroom centers across the state. USU is classified as a high research institution, with a particular emphasis on engineering and education.

USU is also designated as the land grant and space grant institution of the state of Utah. Much emphasis is placed on the university as a public good, as evidenced by part of USU's mission to serve the public through learning, discovery, and engagement.

In support of this mission, our Institutional Repository, the USU Digital Commons, strives to capture, preserve, and provide access to all of the research conducted at Utah State University. To meet this lofty goal, our IR runs on the bepress Digital Commons platform. While we cannot claim to have met this goal, we have been making significant strides towards it since the repository's inception in October of 2008.

Currently, nearly $20 \%$ of the faculty members at Utah State participate in the Digital Commons. This has yielded more than 26,000 records in the repository and greater than 870,000 full-text downloads to date, with 540,000 occurring in the past year. In addition, the repository also hosts several Open Access Journals, all of the USU Press holdings, and student theses, dissertations, presentations, and published materials.

\section{Key to success?}

Our repository is well established and growing rapidly. We have reached a stage where our faculty researchers see the value in depositing their works in the repository, often times independently from the library. To reach this stage, we have benefitted from three key success factors.

First is our reliance on the bepress platform. We have 1 FTE and three student employees dedicated to our repository. Without support from central IT, this level of staffing would be insufficient to operate an open-source system while maintaining the level of outreach we currently devote to the IR. The bepress subscription includes all technical support for the repository. So, the design, implementation, and maintenance of the software is handled by bepress, which allows our Scholarly Communications Librarian to focus on content recruitment, cultivating faculty buy-in, and identifying needs on campus that the IR may be able to fill.

The bepress platform also provides our participating faculty members with a set of download statistics on that faculty member's works on a monthly basis. This, in conjunction with the efficient search engine optimization of the system has been a tremendous help in developing faculty buy-in. Faculty members seem much more enthusiastic about participating in the IR when they are able to see their works highly ranked on Google or Google Scholar and receive download statistics on those works.

Second, we take a we do it for you approach to the IR. With the exception of several partnering research units on campus, our content ingestion process is 
completely centralized. Essentially, we obtain a CV from a faculty member wishing to participate in the IR. Our student employees then add the bibliographic records from the $\mathrm{CV}$ to a formatted spreadsheet for IR ingestion. When completed, students then upload the spreadsheet to the Digital Commons, as well as to a copyright clearance tracking database in FileMaker Pro.

Once this is completed, our Scholarly Communications Librarian creates a personal space within the bepress platform for the faculty member. When that is ready, the Scholarly Communications Librarian alerts the faculty member that the bibliographic information for his or her works has been uploaded. The appropriate Subject Liaison Librarian is CCed here to both draw attention to the other services offered by the library and to alert him or her that the faculty member's works are ready for copyright clearance.

Subject librarians then begin investigating the copyright permissions on each of that faculty member's works. Permissions are marked in the FileMaker Pro database. The people who clear copyright leave specific instructions, and on completion each work is marked "Student." Once all of a particular faculty member's works are cleared, our student employees follow the instructions left by the subject liaison librarians. We then upload full-text files for everything for which we have permission to do so, and we also check the bibliographic records against those on publisher's websites to ensure accuracy.

The third key to our success is that our IR has received tremendous administrative support. The Dean of Libraries, Richard Clement, is very interested in Scholarly Communication and Open Access, and he is a strong supporter of the IR. This support is necessary to acknowledge and maintain the labor involved in developing the IR and helps to build upper-level institutional buy-in for the project for the long term.

\section{The Survey}

As our repository reaches maturity, we are turning our attention from cultivating buy-in and recruiting content, to understanding the end-users of our repository. Our faculty members have been largely impressed with the results of including their works in the repository. Many even report having new life breathed into works that they thought had long exceeded their academic shelf lives.

However, many also questioned the identity of the downloaders of their works. Bepress is COUNTER compliant and even employs an additional stringent set of filters to remove known and unknown crawlers and robots from their download statistics, so we can be fairly sure that the statistics provided stem from legitimate web browsers. So who exactly uses this stuff, anyway?

Beth St. Jean, et al, published an important study on repository end users in early $2011^{1}$. Using qualitative analysis the authors sought to understand end users' perceptions, motivations, trust in the IR, use and search of it, and willingness to use and recommend it. The data provided valuable insights into the end users of repositories. However, the pool of participants, while diverse within the academy, did not extend beyond the academy's boarders. The general public is often perceived to be one of the beneficiaries of open access institutional repositories, 
though, and so, it was important for us to conduct a survey that was not limited strictly to academic researchers.

We took our first step towards understanding the users of our repository by conducting a brief 1-minute survey. The aim of this survey was to capture a portrait of the end-users of our repository, as painted in very broad strokes. In this survey, brevity superseded detail in order to obtain as many responses as possible. Future research, guided by the results of this survey, could then fill in the details.

The survey remained accessible via the Digital Commons for approximately 1 year. Implemented by my predecessor, Heather Leary, in November of 2010, your author concluded the survey in January 2012. The survey was advertised as a "1minute survey" on each metadata record as well as on the cover page of every PDF from November 2010 to July 2011. At this point, the survey link also appeared on the home page of our repository, where it remained until the survey's conclusion. This addition coincided with a large advertising campaign focusing on the IR, which extended through the Fall 2011 semester.

A total of 202 Digital Commons users responded to the survey. Eighty-three of these respondents took the survey during the first eight months, when it appeared only on the records and cover pages. With the addition of the link to the home page and the unveiling of the advertising campaign, this number increased to the final 202 over the remaining six months that the survey was available. As you will see, the majority of our repository users access an individual document through a search engine, and so the boost in participation is likely due more to the advertising campaign than the location of the link.

The First question on our survey asked users to identify their primary role. As expected, graduate and undergraduate students, along with college faculty/staff topped the list, accounting for about $62 \%$ of respondents. The rather large percentage of graduate student respondents (24.8\%), however, is slightly suspect. USU requires all graduate and doctoral students to deposit their thesis or dissertation in the Digital Commons. Future research is needed to determine the purpose of graduate student visits to the repository to tease out those visits that are for the purpose of downloading their own works.

Perhaps most importantly though between 34\% and 39\% of the visitors to the repository identify themselves as primarily unaffiliated with the academy-- The response "Librarian" (5\%) in the survey does not indicate whether the respondent is an academic, public, school, or other librarian. The respondents that self-identify as "interested citizen" and "other" account for $25 \%$ of respondents, with business (5\%), K-12 teacher (2\%), and K-12 student (1.5\%) rounding out the non-academic visitors to the repository.

Moreover, "Other" respondents were asked to elaborate on their roles. Responses such as "natural resource professional," "state Government," "public sector researcher," and "wildlife management professional" indicate that the Digital Commons is of surprising importance to public sector researchers. This is an unexpectedly large end user group of our repository, and as a land grant institution, it is one that we should not ignore. 


\section{Figure One:}

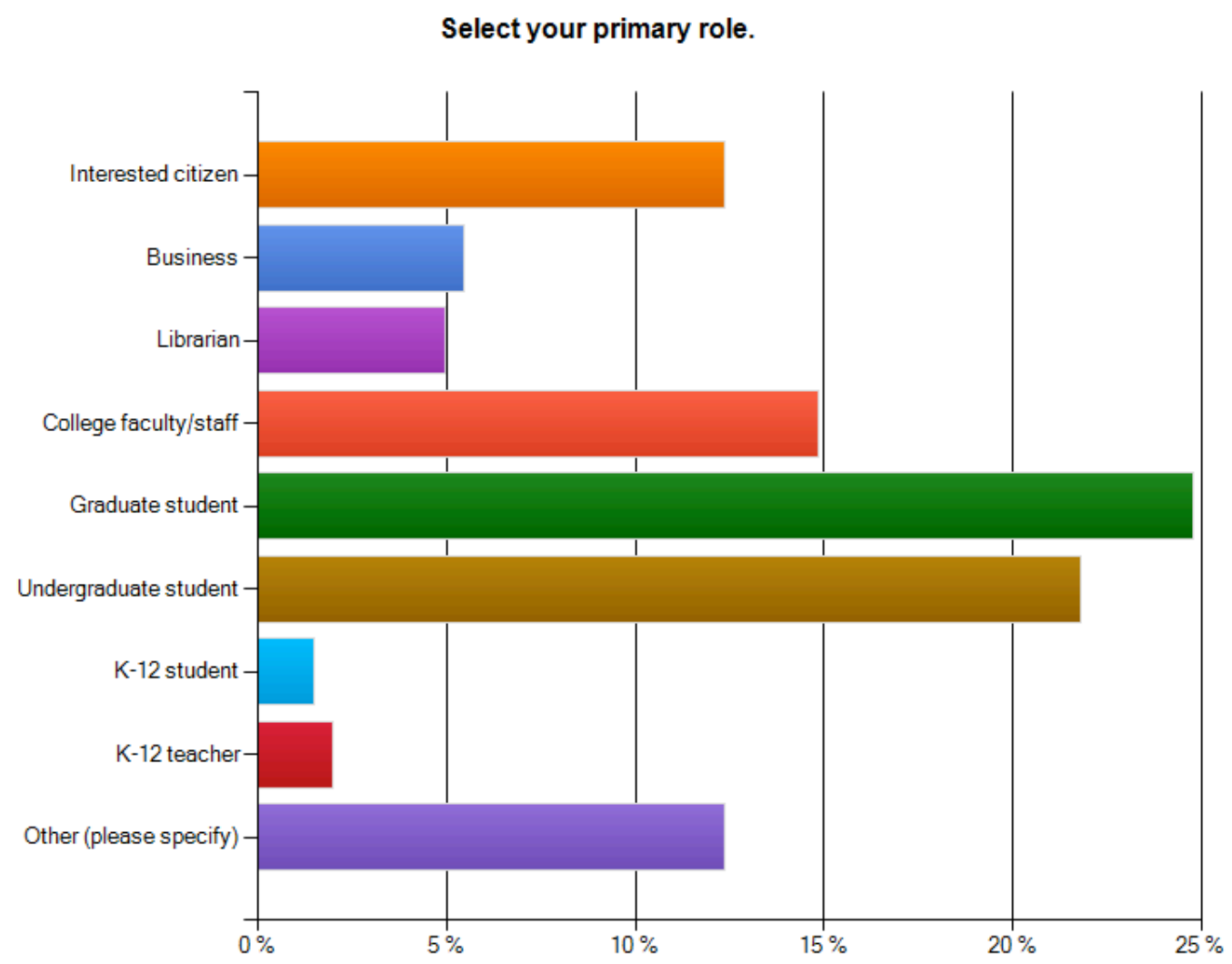

The Second question on our survey asked users to identify their purpose in visiting the repository. As expected, at nearly $75 \%$, most respondents visited the repository for research purposes. In light of the findings from question one, however, future research should more narrowly define the term "research." Finding out the percent of research conducted for academic, business, or other purposes would certainly help in painting a more robust picture of our end-users.

Also of interest, nearly $20 \%$ of our end-users are simply satisfying their curiosity. This is interesting given the high number of non-academic researchers visiting our repository. In addition, it also illustrates an opportunity for us to fulfill our land grant mission through demonstrating value to the public. This seems especially true when the "other" (6.4\%) responses include more public-sector types of research, including "high school and community needs course," "land use management decisions," and "need a coiple [sic] of beef processed." It seems likely that obtaining more detail on the types of research conducted would further increase the prevalence of non-academic researchers. 
Figure 2:

What is your purpose in viewing or downloading this item? (Check all that apply)

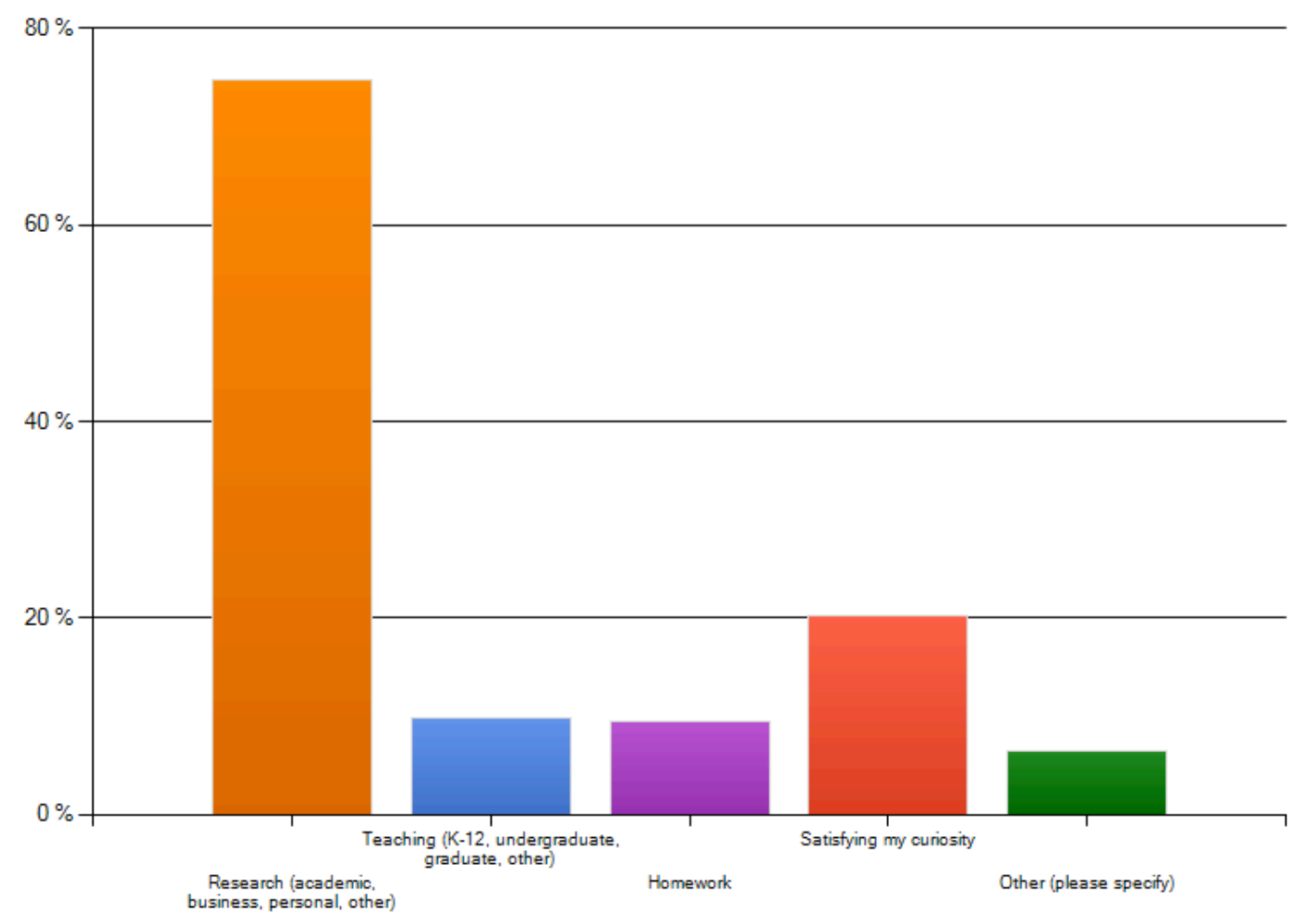

Respondents were then asked how they found material in the Digital Commons. We run Google analytics on our repository, so this question was largely developed to see if information from the end-users of the repository matched the analytics.

Since the repository's inception, Google Analytics indicates that approximately $61 \%$ of our users enter the repository through Google or another search engine. That percentage has increased as the repository has expanded, and during the course of this survey, approximately $64 \%$ of users entered through a search engine.

The survey results, however, indicated that $75 \%$ of end users enter the repository through a search engine. This is expected given the fact that the survey link was initially available only on record pages and PDF cover pages, which are the primary entry points from search engines. However, it also suggests that the addition of the survey link on the home page did not drive up the number of respondents. If this were the case, we would expect the Google analytics and survey results to be more closely aligned. Instead, we suspect that the boost in respondents resulted from our extensive advertising campaign. 
Figure 3:

How did you find this material?

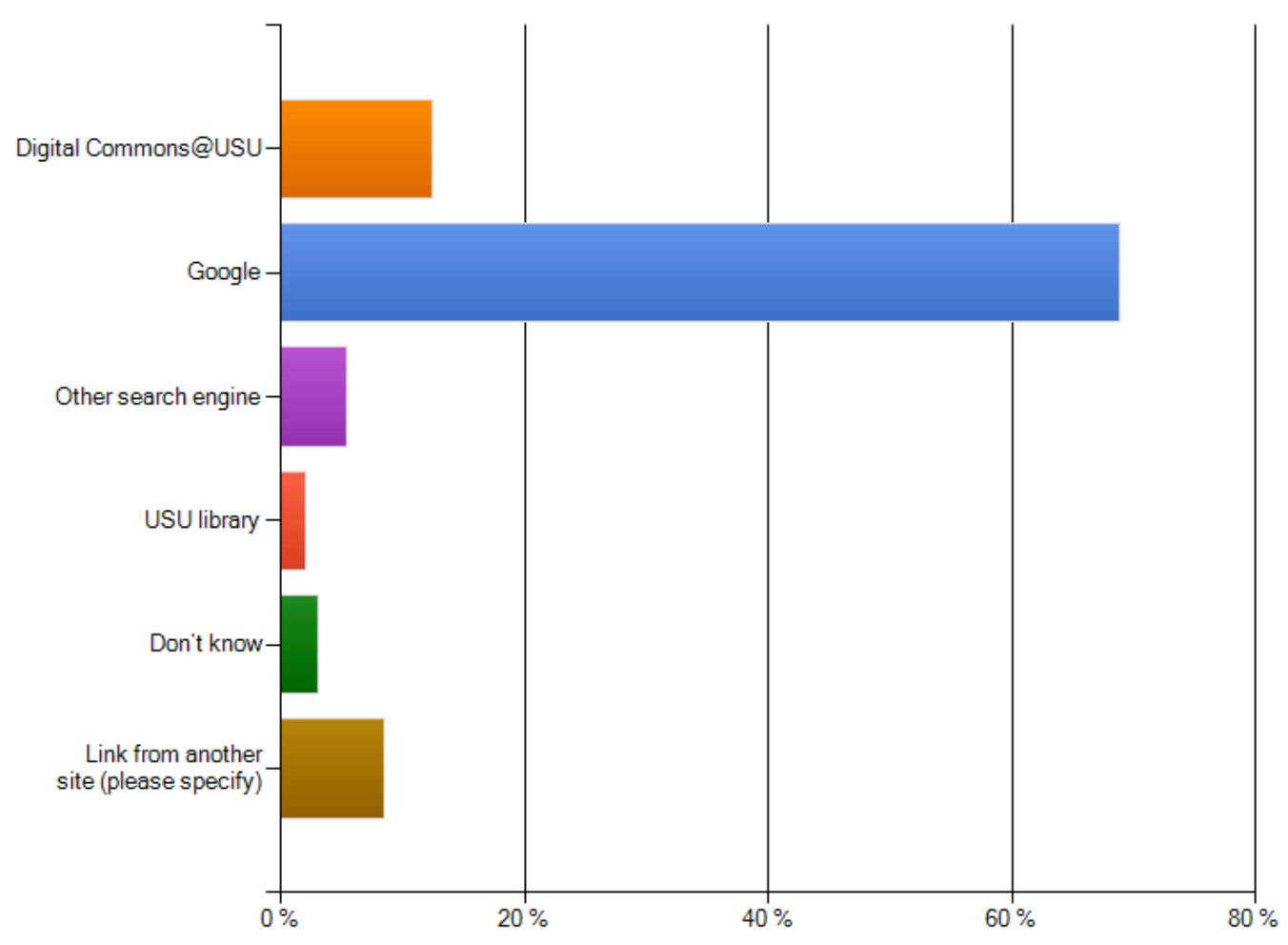

\section{How has this influenced our practice?}

The results of our survey paint a very general picture of our end users-one that is certainly in need of further refinement. We do see, however, that the public is more interested in institutional repositories than we might suppose. This interest is manifested in public-sector research, personally directed research, and the satisfaction of curiosity. As a land grant institution with a mission to serve the public, we should not ignore these findings. With this in mind, this survey has influenced some of our directed collection-development, and has catalyzed some public outreach initiatives.

A significant percentage of the content ingested by our repository comes to us via faculty CVs after we request that they participate in the repository. In addition, though, we typically work on two to three long-term, directed collectiondevelopment projects simultaneously. Ideal candidates for these types of projects include large collections of born-digital or easily digitized materials that fall within the scope of the IR and are perceived to be of some use to our end-users. As a result of our initial survey of end users, we have taken their perceived needs into consideration when selecting long-term projects.

To this end, we are currently building two collections that directly address the needs of our end users as evidenced by the survey. First, we are building a collection to represent the published and unpublished works of Joel Ricks-a 
prominent USU history professor, whose research primarily focused on the history of Cache Valley and the region. Second, we have begun uploading historical extension bulletins in hopes that they could prove valuable to some of the publicsector researchers who visit our repository.

In addition, we are beginning to raise public awareness of our unique, free, online resources found both in our institutional repository and our digital library. We accomplish this by collecting content perceived to be of public interest, then presenting that content in public venues. Initially, we have done this at a local branch of a for-profit college, as well as given presentations to the Cache Valley Library Association. The latter is composed of academic, public, and school librarians, many of whom interact with the public on a daily basis.

\section{Conclusions}

As our repository matures, it is necessary for us to better understand who our end users are and what their needs might be. While this survey did not provide extensive detail about our end users, it did take the important step of identifying users who do not indicate any affiliation with the academy. This information will provide a platform for future research as well as a direction for our current collection-development efforts.

\section{Notes:}

Andrew Wesolek is the Scholarly Communications Librarian at Utah State University.

1. Beth St. Jean, et al. "Unheard Voices: Institutional Repository End-Users," College and Research Libraries 72, no. 1 (January 2011): 21-42. 